Acta Crystallographica Section C

\section{Crystal Structure}

Communications

ISSN 0108-2701

\section{Polymorphism in an unexpected caesium complex of 5-hydroxy- hydurilic acid}

\section{Gary S. Nichol and William Clegg*}

School of Natural Sciences (Chemistry), Bedson Building, University of Newcastle, Newcastle upon Tyne NE1 7RU, England

Correspondence e-mail: w.clegg@ncl.ac.uk

Received 14 September 2005

Accepted 15 September 2005

Online 30 September 2005

Vigorous reaction of barbituric acid with caesium hydroxide in water resulted in an unexpected coupling product, 5-hydroxyhydurilic acid, complexed to caesium, giving poly[[caesium$\mu_{5}$-5-hydroxyhydurilato $]$ hemihydrate $], \quad\left\{\left[\mathrm{Cs}\left(\mathrm{C}_{8} \mathrm{H}_{5} \mathrm{~N}_{4} \mathrm{O}_{7}\right)\right] \cdot-\right.$ $\left.0.5 \mathrm{H}_{2} \mathrm{O}\right\}_{n}$. This was obtained in two different polymorphic forms, depending on the method of crystal growth. Slow solvent evaporation yielded an orthorhombic polymorph, (I), which crystallized in the space group Pnab (non-standard setting of $P b c n$ ), with the uncoordinated water molecule lying on a crystallographic twofold axis. The water molecule is sandwiched into cavities within the structure and is securely held in place by $\mathrm{N}-\mathrm{H} \cdots \mathrm{O}$ and $\mathrm{O}-\mathrm{H} \cdots \mathrm{O}$ hydrogen bonding. Polymorph (II) is monoclinic, although the unit-cell parameters are similar to those of polymorph (I), and it crystallizes in the space group $C 2 / c$, with the uncoordinated water molecule again lying on the twofold axis and secured by hydrogen bonding. The differences between the two polymorphs, both of which have nine-coordinate caesium and a similar first-shell environment of all structural components, are in the overall arrangement of the cations, anions and water molecules, and in the shape of the cavities, revealed by inspecting and comparing crystal-packing diagrams.

\section{Comment}

Barbituric acid is a simple molecule which has been much studied in recent times due to its propensity to form polymorphs and, as a result, it has been used as a model compound for developing computational polymorph prediction techniques (Lewis et al., 2004). One of the major obstacles to the success of this research has been the partial flexibility of the molecule, which makes successful polymorph modelling particularly tricky (Lewis et al., 2005). Recently, we demonstrated that this molecular flexibility allows the crystal structure of barbituric acid dihydrate to undergo a phase transition at low temperatures (Nichol \& Clegg, 2005).

During the preparation of some alkali metal complexes of barbituric acid, we exposed the reaction with caesium hydrox- ide to more vigorous conditions than had been used for $\mathrm{Li}-\mathrm{Rb}$ in order to reduce the solution volume. The result was an unexpected barbiturate coupling product, 5-hydroxyhydurilic

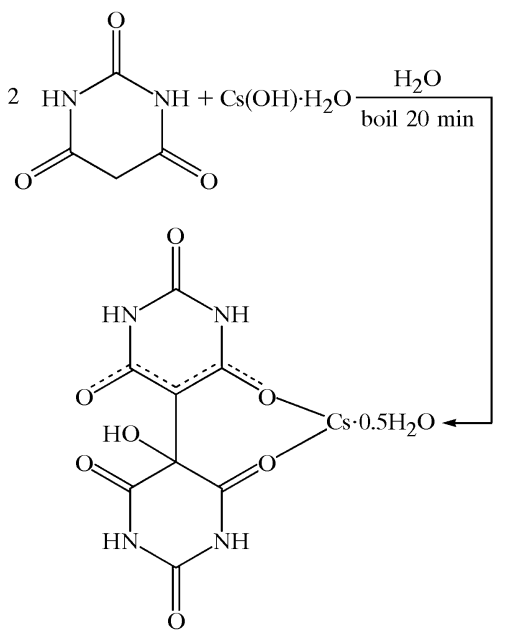

(I), (II)

acid (5-hydroxy-5,5'-bibarbituric acid) (see scheme), which coordinated in its anionic form to caesium. Repeating the reaction but with only brief heating of the reaction solution gave a normal barbiturate complex, as for the other alkali metals. We have also observed this same coupling when 1,8bis(dimethylamino)naphthalene (a proton sponge) was used as the base in a methanolic solution of barbituric acid, so the actual base and solvent used would not seem to be determining factors for the reaction. 5-Hydroxyhydurilic acid itself is rather unusual; it is not commercially available and the only reported synthesis to date is by electrochemical oxidation of hydurilic acid (and so not actually a barbiturate coupling reaction; Kato et al., 1975).

Crystallization of the reaction product gave two polymorphic forms, (I) and (II). Crystallization by slow solvent evaporation gave polymorph (I) in the orthorhombic space group Pbcn (reported here in the alternative setting Pnab, so that the axes match those in the second polymorph); the space

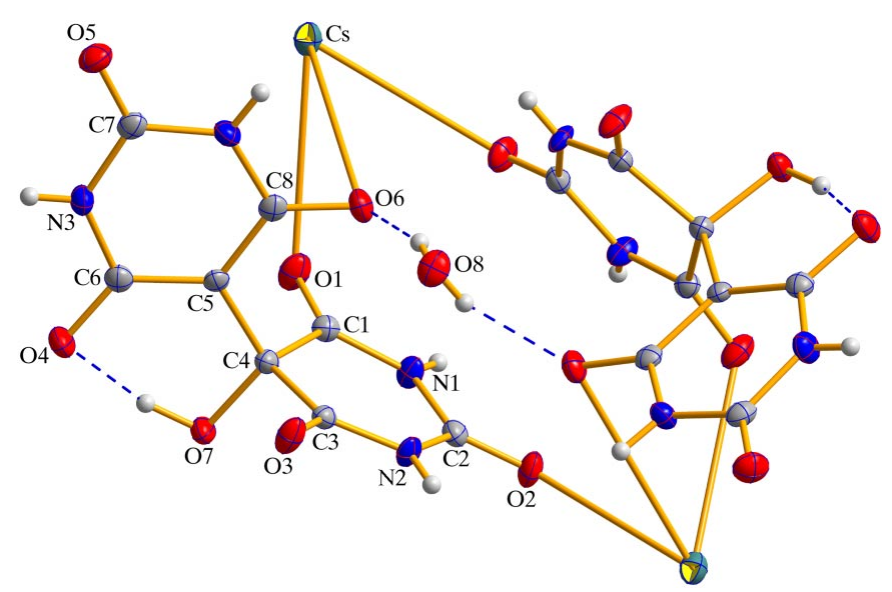

Figure 1

The structural unit of polymorph (I), shown with $50 \%$ probability displacement ellipsoids. Dashed lines indicate selected hydrogen bonds. 
group determination was unambiguous from the systematic absences. The structural unit of polymorph (I) is presented in Fig. 1 and is twice the size of the asymmetric unit. It consists of two caesium-5-hydroxyhydurilate complexes related by a twofold rotation about a non-coordinated but hydrogenbonded water molecule. The water molecule acts as a donor in two $\mathrm{O}-\mathrm{H} \cdots \mathrm{O}$ interactions and as an acceptor in two $\mathrm{N}-$ $\mathrm{H}$... O interactions (Table 2) and so is pseudo-tetrahedral. Additional intramolecular hydrogen bonding secures the location of the $\mathrm{OH}$ group into an $S(6)$ ring (Bernstein et al., 1995). The Cs ion is nine-coordinate (not shown in full in Fig. 1) and the $\mathrm{Cs}-\mathrm{O}$ bond lengths range from the relatively short 2.981 (2) A to the rather long 3.531 (2) A (Table 1). One of the rings of the 5-hydroxyhydurilate ligand is essentially planar (r.m.s. deviation from a mean plane fitted through the non-H atoms is $0.012 \AA$ ), as is usually observed in deprotonated barbituric acid, whilst the second ring contains an $s p^{3}$ hybridized $\mathrm{C}$ atom, which is displaced slightly out of the ring of the remaining non-H atoms (r.m.s. deviation $0.078 \AA$ ); the angle between the two mean planes is $85.6(2)^{\circ}$. The two new bonds formed in the coupling reaction are $\mathrm{C} 4-\mathrm{C} 5$ and $\mathrm{C} 4-$ O7, which have lengths of 1.502 (4) and 1.439 (3) $\AA$, respectively, indicating that both are single bonds. The hydroxy $\mathrm{H}$ atom was easily located in a difference electron-density map, confirming that the $\mathrm{C} 4-\mathrm{O} 7$ bond is single in character. In the planar ring, bonding is delocalized over the O4-C6-C5$\mathrm{C} 8-\mathrm{O} 6$ segment, with each bond intermediate between single and double.

A monoclinic polymorph, (II), was obtained by storing the solution at approximately $278 \mathrm{~K}$ for several months. Although the unit-cell parameters of polymorph (II) are similar to those of polymorph (I), this is for a $C$-centred rather than a primitive unit cell. The structural unit of polymorph (II) is shown in Fig. 2. Like polymorph (I), polymorph (II) crystallizes with one non-coordinating water molecule on a twofold rotation axis, and so the asymmetric unit is one half of the structural unit. Also, as in polymorph (I), the water molecule is secured

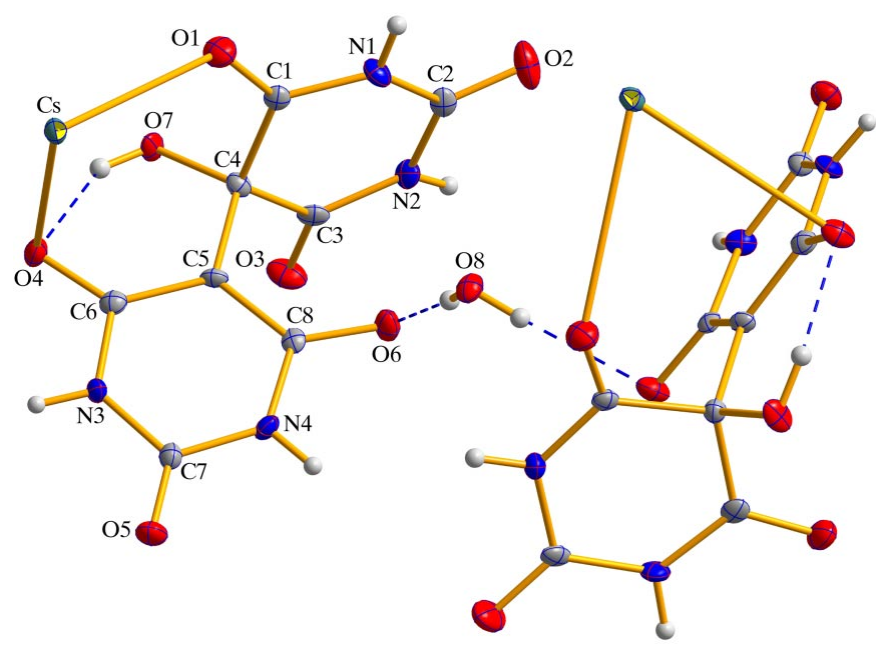

Figure 2

The structural unit of polymorph (II), shown with $50 \%$ probability displacement ellipsoids. Dashed lines indicate selected hydrogen bonds. in place by four hydrogen bonds, as donor for two and as acceptor for the other two, with additional intramolecular hydrogen bonding securing the position of the hydroxy $\mathrm{H}$ atom (Table 4). The Cs ion is again nine-coordinate, but the range of bond lengths is much wider, from 2.983 (4) to 3.690 (4) $\AA$ (Table 3), which is distinctly long for a Cs-O bond, but not unknown. The two 5-hydroxyhydurilate rings are either essentially planar (r.m.s. deviation $0.007 \AA$ for one) or slightly distorted (r.m.s. deviation $0.090 \AA$ for the other), as is seen in polymorph (I), although in polymorph (II), the angle between their two mean planes is slightly smaller, at $78.3(2)^{\circ}$. Also in common with polymorph (I), the $\mathrm{C} 4-\mathrm{C} 5$ and $\mathrm{C} 4-\mathrm{O} 7$ bond lengths are 1.531 (6) and 1.421 (6) $\AA$, respectively, indicating single-bond character.

If the individual structural units of polymorphs (I) and (II) give little indication that these are two different polymorphic structures, then their respective packing diagrams are more revealing. Fig. 3 shows two $b$-axis projections of polymorphs (I) (top) and (II) (bottom). Setting polymorph (I) in space group Pnab allows a direct comparison to be made between the two, as the cell axes are now approximately equal. Both are three-dimensional structures featuring columns of quadruply bridged Cs centres. These columns are then linked together by further coordination from the second ring of the ligand across to a Cs centre of another column. This linkage creates what appear to be channels within the structure, sandwiched inside which are securely hydrogen-bonded pseudo-tetrahedral water molecules. Inspection of spacefilling models, however, shows that the water molecules lie in
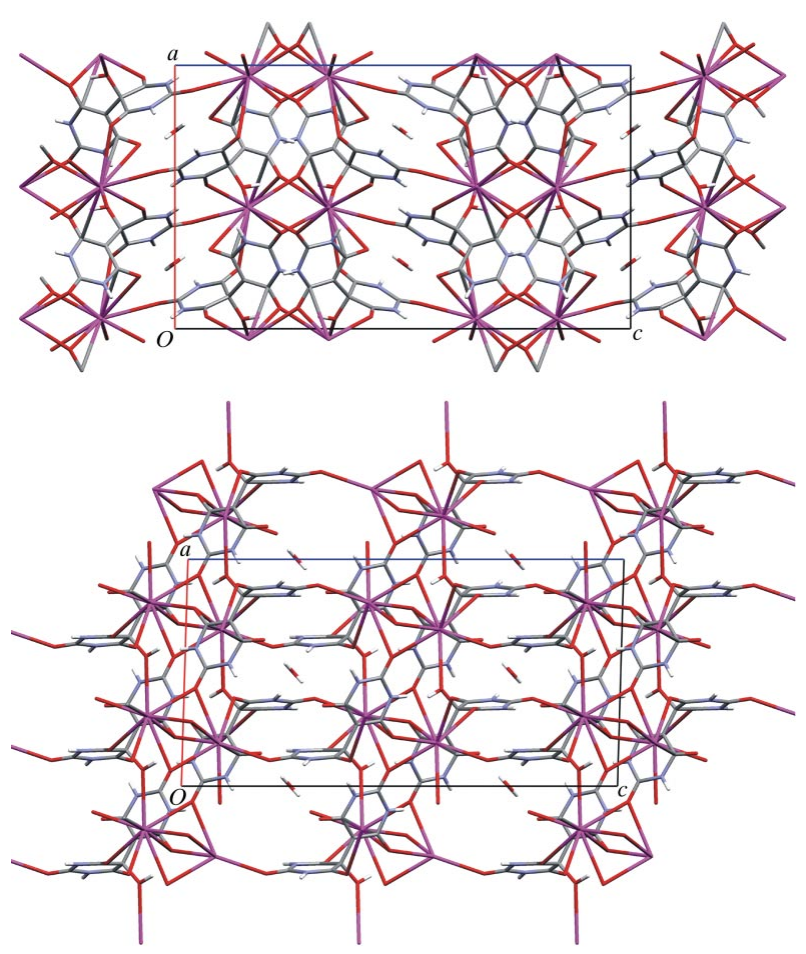

Figure 3

Packing diagrams, projected along the $b$ axes, for polymorphs (I) (top) and (II) (bottom). 
individual cavities, between which there are only restricted openings. The differences between the two packing diagrams are in the overall arrangement of the cations, anions and water molecules, and in the shape of the cavities. These are most easily seen by concentrating on the water-filled cavities. In polymorph (I), these apparent channels are arranged such that the overall impression is one of 'ripples' within the structure along the $c$ axis. In polymorph (II), there is no such rippling and the apparent channels are stacked ladder-like in a regular rectangular grid.

\section{Experimental}

$\mathrm{CsOH} \cdot \mathrm{H}_{2} \mathrm{O}(0.171 \mathrm{~g}, 1 \mathrm{mmol})$ and barbituric acid $(0.132 \mathrm{~g}, 1 \mathrm{mmol})$ were dissolved in distilled water (approximately $30 \mathrm{ml}$ ), and the solution was boiled until approximately $10 \mathrm{ml}$ remained. Slow evaporation of a small amount of solvent over a period of one week yielded some very small crystals of polymorph (I). Storage of the solution at approximately $278 \mathrm{~K}$ for around five months yielded small crystal clusters of polymorph (II).

\section{Polymorph (I)}

\section{Crystal data \\ $\left[\mathrm{Cs}\left(\mathrm{C}_{8} \mathrm{H}_{5} \mathrm{~N}_{4} \mathrm{O}_{7}\right)\right] \cdot 0.5 \mathrm{H}_{2} \mathrm{O}$ \\ $M_{r}=411.08$ \\ Orthorhombic, Pnab \\ $a=13.6671(8) \AA$ \\ $b=7.0632$ (4) $\AA$ \\ $c=23.5991(17) \AA$ \\ $V=2278.1(2) \AA^{3}$ \\ $Z=8$ \\ $D_{x}=2.397 \mathrm{Mg} \mathrm{m}^{-3}$}

\section{Data collection}

Nonius KappaCCD area-detector diffractometer

$\varphi$ and $\omega$ scans

Absorption correction: multi-scan

(SADABS; Sheldrick, 2003)

$T_{\text {min }}=0.681, T_{\max }=0.723$

49241 measured reflections

\section{Refinement}

Refinement on $F^{2}$

$R\left[F^{2}>2 \sigma\left(F^{2}\right)\right]=0.025$

$w R\left(F^{2}\right)=0.047$

$S=1.05$

2592 reflections

204 parameters

Only $\mathrm{H}$-atom coordinates refined

\author{
Mo $K \alpha$ radiation \\ Cell parameters from 19019 \\ reflections \\ $\theta=2.5-27.5^{\circ}$ \\ $\mu=3.30 \mathrm{~mm}^{-1}$ \\ $T=150(2) \mathrm{K}$ \\ Block, colourless \\ $0.30 \times 0.10 \times 0.10 \mathrm{~mm}$
}

2592 independent reflections 2146 reflections with $I>2 \sigma(I)$

$R_{\text {int }}=0.065$

$\theta_{\text {max }}=27.5^{\circ}$

$h=-17 \rightarrow 17$

$k=-9 \rightarrow 8$

$l=-30 \rightarrow 30$

$$
\begin{gathered}
w=1 /\left[\sigma^{2}\left(F_{\mathrm{o}}^{2}\right)+(0.0137 P)^{2}\right. \\
+4.4877 P] \\
\text { where } P=\left(F_{\mathrm{o}}{ }^{2}+2 F_{\mathrm{c}}{ }^{2}\right) / 3 \\
(\Delta / \sigma)_{\max }<0.001 \\
\Delta \rho_{\max }=0.68 \mathrm{e} \AA^{-3} \\
\Delta \rho_{\min }=-0.45 \AA^{-3}
\end{gathered}
$$

Table 1

Selected geometric parameters $\left(\AA,^{\circ}\right)$ for polymorph (I).

\begin{tabular}{|c|c|c|c|c|}
\hline$D-\mathrm{H} \cdots A$ & $D-\mathrm{H}$ & $\mathrm{H} \cdots A$ & $D \cdots A$ & $D-\mathrm{H} \cdots A$ \\
\hline $\mathrm{O} 7-\mathrm{H} 7 \cdots \mathrm{O} 4$ & $0.93(3)$ & $1.65(3)$ & $2.563(3)$ & $164(3)$ \\
\hline $\mathrm{O} 8-\mathrm{H} 8 \cdots \mathrm{O} 6$ & $0.72(3)$ & $2.08(3)$ & $2.780(3)$ & $163(4)$ \\
\hline $\mathrm{N} 1-\mathrm{H} 1 \mathrm{~N} \cdots \mathrm{O}^{\mathrm{v}}$ & $0.74(3)$ & $2.16(3)$ & $2.865(3)$ & $161(3)$ \\
\hline $\mathrm{N} 2-\mathrm{H} 2 \mathrm{~N} \cdots \mathrm{O} 3^{\mathrm{vii}}$ & $0.73(3)$ & $2.09(3)$ & $2.816(3)$ & $174(3)$ \\
\hline $\mathrm{N} 3-\mathrm{H} 3 \mathrm{~N} \cdots \mathrm{O} 1^{\text {viii }}$ & $0.75(3)$ & $2.57(3)$ & $3.151(3)$ & $136(3)$ \\
\hline $\mathrm{N} 4-\mathrm{H} 4 \mathrm{~N} \cdots \mathrm{O} 7^{\mathrm{ii}}$ & $0.82(3)$ & $2.29(3)$ & $3.005(3)$ & $147(3)$ \\
\hline
\end{tabular}

\begin{tabular}{llll}
\hline $\mathrm{Cs}-\mathrm{O} 1$ & $3.352(2)$ & $\mathrm{O} 4-\mathrm{C} 6$ & $1.267(3)$ \\
$\mathrm{Cs}-\mathrm{O} 2^{\mathrm{i}}$ & $3.2119(19)$ & $\mathrm{O} 6-\mathrm{C} 8$ & $1.253(3)$ \\
$\mathrm{Cs}-\mathrm{O} 3^{\mathrm{ii}}$ & $3.1808(19)$ & $\mathrm{O} 7-\mathrm{C} 4$ & $1.439(3)$ \\
$\mathrm{Cs}-\mathrm{O} 4^{\mathrm{iii}}$ & $3.1361(19)$ & $\mathrm{C} 1-\mathrm{C} 4$ & $1.542(4)$ \\
$\mathrm{Cs}-\mathrm{O} 4^{\mathrm{ii}}$ & $3.469(2)$ & $\mathrm{C} 3-\mathrm{C} 4$ & $1.530(4)$ \\
$\mathrm{Cs}-\mathrm{O} 5^{\mathrm{iv}}$ & $2.981(2)$ & $\mathrm{C} 4-\mathrm{C} 5$ & $1.502(4)$ \\
$\mathrm{Cs}-\mathrm{O} 5^{\mathrm{v}}$ & $3.320(2)$ & $\mathrm{C} 5-\mathrm{C} 6$ & $1.395(4)$ \\
$\mathrm{Cs}-\mathrm{O} 6$ & $3.531(2)$ & $\mathrm{C} 5-\mathrm{C} 8$ & $1.399(4)$ \\
$\mathrm{Cs}-\mathrm{O} 7^{\mathrm{vi}}$ & $3.040(2)$ & & \\
$\mathrm{C} 1-\mathrm{C} 4-\mathrm{C} 3$ & $113.3(2)$ & $\mathrm{C} 6-\mathrm{C} 5-\mathrm{C} 8$ & $120.7(2)$
\end{tabular}

Symmetry codes: (i) $-x+\frac{1}{2}, y,-z$; (ii) $x-\frac{1}{2},-y+1, z$; (iii) $x-\frac{1}{2},-y+\frac{1}{2},-z+\frac{1}{2}$; (iv) $x, y-\frac{1}{2},-z+\frac{1}{2}$; (v) $x, y-1, z ;$ (vi) $x-\frac{1}{2},-y, z$.
Table 2

Hydrogen-bond geometry $\left(\AA,^{\circ}\right)$ for polymorph (I).

\begin{tabular}{|c|c|}
\hline$\left[\mathrm{Cs}\left(\mathrm{C}_{8} \mathrm{H}_{5} \mathrm{~N}_{4} \mathrm{O}_{7}\right)\right] \cdot 0.5 \mathrm{H}_{2} \mathrm{O}$ & $D_{x}=2.381 \mathrm{Mg} \mathrm{m}^{-3}$ \\
\hline$M_{r}=411.08$ & Mo $K \alpha$ radiation \\
\hline $\begin{array}{l}\text { Monoclinic, } C 2 / c \\
a=12.1244(16) \AA\end{array}$ & $\begin{array}{l}\text { Cell parameters from } 7338 \\
\text { reflections }\end{array}$ \\
\hline$b=8.1353(11) \AA$ & $\theta=3.0-28.2^{\circ}$ \\
\hline$c=23.267(3) \AA$ & $\mu=3.28 \mathrm{~mm}^{-1}$ \\
\hline$\beta=91.654(2)^{\circ}$ & $T=150(2) \mathrm{K}$ \\
\hline$V=2294.0(5) \AA^{3}$ & Block, colourless \\
\hline$Z=8$ & $0.30 \times 0.18 \times 0.15 \mathrm{~mm}$ \\
\hline
\end{tabular}

Symmetry codes: (ii) $x-\frac{1}{2},-y+1, z$; (v) $x, y-1, z$; (vii) $-x+1,-y+1,-z$; (vii) $x, y+\frac{1}{2},-z+\frac{1}{2}$.

\section{Polymorph (II)}

Crystal data

\section{Data collection}

Bruker SMART 1K CCD area-

detector diffractometer

Thin-slice $\omega$ scans

Absorption correction: multi-scan (SADABS; Sheldrick, 2003)

$T_{\min }=0.494, T_{\max }=0.612$

10061 measured reflections

2765 independent reflections 2661 reflections with $I>2 \sigma(I)$

$R_{\text {int }}=0.031$

$\theta_{\max }=28.2^{\circ}$

$h=-16 \rightarrow 15$

$k=-10 \rightarrow 10$

$l=-30 \rightarrow 30$

\section{Refinement}

Refinement on $F^{2}$

$R\left[F^{2}>2 \sigma\left(F^{2}\right)\right]=0.044$

$w R\left(F^{2}\right)=0.082$

$S=1.42$

2765 reflections

204 parameters
$\mathrm{H}$ atoms treated by a mixture of independent and constrained refinement
$w=1 /\left[\sigma^{2}\left(F_{\mathrm{o}}^{2}\right)+28.7093 P\right]$
where $P=\left(F_{\mathrm{o}}^{2}+2 F_{\mathrm{c}}^{2}\right) / 3$

\begin{tabular}{|c|c|c|c|}
\hline $\mathrm{Cs}-\mathrm{O} 2^{\mathrm{i}}$ & $2.983(4)$ & $\mathrm{O} 4-\mathrm{C} 6$ & $1.260(6)$ \\
\hline $\mathrm{Cs}-\mathrm{O}^{\mathrm{ii}}$ & $3.151(4)$ & $\mathrm{O} 6-\mathrm{C} 8$ & $1.269(6)$ \\
\hline $\mathrm{Cs}-\mathrm{O} 1$ & $3.190(4)$ & $\mathrm{O} 7-\mathrm{C} 4$ & $1.421(6)$ \\
\hline $\mathrm{Cs}-\mathrm{O} 4$ & $3.318(4)$ & $\mathrm{C} 3-\mathrm{C} 4$ & $1.534(7)$ \\
\hline $\mathrm{Cs}-\mathrm{O} 4^{\mathrm{iii}}$ & 3.009 (3) & $\mathrm{C} 4-\mathrm{C} 1$ & $1.536(7)$ \\
\hline $\mathrm{Cs}-\mathrm{O}^{\mathrm{iv}}$ & $3.030(3)$ & $\mathrm{C} 4-\mathrm{C} 5$ & $1.531(6)$ \\
\hline $\mathrm{Cs}-\mathrm{O} 5^{\mathrm{v}}$ & 3.181 (4) & $\mathrm{C} 5-\mathrm{C} 6$ & $1.403(7)$ \\
\hline $\mathrm{Cs}-\mathrm{O} 6^{\mathrm{ii}}$ & $3.690(4)$ & $\mathrm{C} 5-\mathrm{C} 8$ & $1.402(6)$ \\
\hline $\mathrm{Cs}-\mathrm{O}^{\mathrm{vi}}$ & $3.232(4)$ & & \\
\hline $\mathrm{C} 3-\mathrm{C} 4-\mathrm{C} 1$ & $113.9(4)$ & $\mathrm{C} 6-\mathrm{C} 5-\mathrm{C} 8$ & $120.0(4)$ \\
\hline
\end{tabular}
$(\Delta / \sigma)_{\max }=0.001$
$\Delta \rho_{\max }=1.49 \mathrm{e}^{-3}$
$\Delta \rho_{\min }=-2.50 \mathrm{e}^{-3}$

Table 3

Selected geometric parameters $\left(\AA{ }^{\circ}\right)$ for polymorph (II).

Symmetry codes: (i) $-x+\frac{3}{2}, y-\frac{1}{2},-z+\frac{3}{2}$; (ii) $x, y-1, z$; (iii) $-x+\frac{3}{2},-y-\frac{1}{2},-z+2$; (iv) $-x+1,-y,-z+2 ;$ (v) $x+\frac{1}{2}, y-\frac{1}{2}, z$; (vi) $x-\frac{1}{2}, y-\frac{1}{2}, z$.

All $\mathrm{H}$ atoms were located in difference Fourier maps. For polymorph $(\mathrm{I})$, their coordinates were refined freely, with $U_{\text {iso }}(\mathrm{H})=$ $1.2 U_{\text {eq }}(\mathrm{O}, \mathrm{N})$; the $\mathrm{N}-\mathrm{H}$ distance range is 0.74 (3) -0.82 (3) $\AA$, and $\mathrm{O}-$ $\mathrm{H}$ distances are 0.93 (3) $\AA$ for the $\mathrm{C}-\mathrm{OH} \mathrm{H}$ atom and 0.72 (3) $\AA$ for the water $\mathrm{H}$ atom. For polymorph (II), N-H bond lengths were restrained to 0.85 (3) $\AA$, but $\mathrm{O}-\mathrm{H}$ distances were not restrained; the $\mathrm{O}-\mathrm{H}$ distances refined to 0.85 (7) $\AA$ for the $\mathrm{C}-\mathrm{OH} \mathrm{H}$ atom and 0.79 (6) $\AA$ for the water $\mathrm{H}$ atom. 


\section{metal-organic compounds}

Table 4

Hydrogen-bond geometry $\left(\AA,^{\circ}\right)$ for polymorph (II).

\begin{tabular}{|c|c|c|c|c|}
\hline$D-\mathrm{H} \cdots A$ & $D-\mathrm{H}$ & $\mathrm{H} \cdots A$ & $D \cdots A$ & $D-\mathrm{H} \cdots A$ \\
\hline $\mathrm{O} 7-\mathrm{H} 7 \cdots \mathrm{O} 4$ & $0.85(7)$ & $1.78(7)$ & $2.567(5)$ & $154(6)$ \\
\hline $\mathrm{O} 8-\mathrm{H} 8 \cdots \mathrm{O} 6$ & $0.79(6)$ & $2.03(6)$ & $2.817(5)$ & $176(6)$ \\
\hline $\mathrm{N} 2-\mathrm{H} 2 \mathrm{~N} \cdots \mathrm{O}^{\mathrm{vii}}$ & $0.86(3)$ & $2.04(3)$ & $2.864(6)$ & $162(6)$ \\
\hline $\mathrm{N} 1-\mathrm{H} 1 \mathrm{~N} \cdots \mathrm{O} 6^{\mathrm{i}}$ & $0.85(3)$ & $2.16(3)$ & $3.006(5)$ & $176(6)$ \\
\hline $\mathrm{N} 3-\mathrm{H} 3 \mathrm{~N} \cdots \mathrm{O} 3^{\text {viii }}$ & $0.83(3)$ & $2.52(3)$ & $3.323(6)$ & $164(6)$ \\
\hline $\mathrm{N} 4-\mathrm{H} 4 \mathrm{~N} \cdots \mathrm{O} 1^{\mathrm{ix}}$ & $0.84(3)$ & $2.18(3)$ & $3.005(6)$ & $168(6)$ \\
\hline
\end{tabular}

Symmetry codes: (i) $-x+\frac{3}{2}, y-\frac{1}{2},-z+\frac{3}{2}$; (vii) $x+\frac{1}{2}, y+\frac{1}{2}, z$; (viii) $-x+\frac{3}{2},-y+\frac{1}{2}$, $-z+2$; (ix) $x-\frac{1}{2}, y+\frac{1}{2}, z$.

Data collection: COLLECT (Nonius, 1998) for polymorph (I); $S M A R T$ (Bruker, 2001) for polymorph (II). Cell refinement: EVALCCD (Duisenberg et al., 2003) for polymorph (I); SAINT (Bruker, 2001) for polymorph (II). Data reduction: $E V A L C C D$ for polymorph (I); SAINT for polymorph (II). For both compounds, program(s) used to solve structure: SHELXTL (Sheldrick, 2001); program(s) used to refine structure: $S H E L X T L$; molecular graphics: DIAMOND (Brandenburg \& Putz, 2004) and MERCURY (Version 1.4; Bruno et al., 2002); software used to prepare material for publication: SHELXTL and local programs.
The authors thank the EPSRC for funding.

Supplementary data for this paper are available from the IUCr electronic archives (Reference: SK1870). Services for accessing these data are described at the back of the journal.

\section{References}

Bernstein, J., Davis, R. E., Shimoni, L. \& Chang, N.-L. (1995). Angew. Chem. Int. Ed. Engl. 34, 1555-1573.

Brandenburg, K. \& Putz, H. (2004). DIAMOND. Version 3.0. University of Bonn, Germany.

Bruker (2001). SMART and SAINT. Bruker AXS Inc., Madison, Wisconsin, USA.

Bruno, I. J., Cole, J. C., Edgington, P. R., Kessler, M., Macrae, C. F., McCabe, P., Pearson, J. \& Taylor, R. (2002). Acta Cryst. B58, 389-397.

Duisenberg, A. J. M., Kroon-Batenburg, L. M. J. \& Schreurs, A. M. M. (2003). J. Appl. Cryst. 36, 220-229.

Kato, S., Visinski, B. M. \& Dryhurst, G. (1975). J. Electroanal. Chem. 66, 21-43.

Lewis, T. C., Tocher, D. A. \& Price, S. L. (2004). Cryst. Growth Des. 4, 979-987.

Lewis, T. C., Tocher, D. A. \& Price, S. L. (2005). Cryst. Growth Des. 5, 983-993.

Nichol, G. S. \& Clegg, W. (2005). Acta Cryst. B61, 464-472.

Nonius (1998). COLLECT. Nonius BV, Delft, The Netherlands.

Sheldrick, G. M. (2001). SHELXTL. Version 6.0. Bruker AXS Inc., Madison, Wisconsin, USA.

Sheldrick, G. M. (2003). SADABS. University of Göttingen, Germany. 